\title{
A Wind Powered, White LED Lighting System for the Kibera Slum of Nairobi
}

\author{
Brian Thomas \\ Lecturer, Department of Electrical and Computer Engineering \\ Baylor University \\ Brian_Thomas@baylor.edu
}

\begin{abstract}
A multidisciplinary team of engineering students traveled to Nairobi, Kenya in May 2006 to implement a service learning project between academic sessions. Low power, white light emitting diode (WLED) based lighting devices were designed and built by student participants and members of the student organization Engineers with a Mission during the months preceding the trip. Photometric performance and power consumption data are given for these devices, which were subsequently installed in seventeen homes in the large and infamous Kibera slum ${ }^{i}$. A locally manufactured, technologically appropriate wind generator was purchased and installed to charge a single, centrally located deep cycle battery. Power from this battery was distributed to the LED-based lights through a student designed and built circuit breaker panel and a radial network of indoor/outdoor extension cords that served as low voltage transmission lines. The project provided a learning environment for alternative energy techniques, appropriate technologies, global and multicultural awareness, poverty apprehension, the realities of project implementation, and the social responsibility of those in the engineering profession. A network of Kenyan organizations consisting of a university, a non-governmental organization, a small business, and a community organization, was formed to facilitate sustainability and provide ongoing analysis and maintenance.
\end{abstract}

Index Terms - appropriate technology, Kibera, wind power, WLED.

\section{INTRODUCTION}

This paper describes an engineering project undertaken by Baylor University ${ }^{\mathrm{ii}}$ and shows that international service projects can be a valuable part of undergraduate engineering education. The author of this paper was the faculty mentor for a team of seven engineering students. This section will provide background information on the needs for, and objectives of, this endeavor.

\section{Background Information on Kibera:}

Kibera is one of Africa's largest slums with population near 1,000,000 and is home to about one third of Nairobi's population. It is located within Nairobi, in a densely populated area of only about 630 acres. Life there is a daily struggle with poverty, crime, and disease. Many Kibera residents work in Nairobi's industrial sector for wages near \$1 USD per day ${ }^{\mathrm{iii}}$. The typical family of five lives in a three meter by three meter home without plumbing. Rusting corrugated steel roofing is ubiquitous and multitudinous footpaths form an apparent labyrinth of muddy narrow walkways and open sewers. Only a small minority have electricity. As many as 400 people can end up sharing one toilet in one of the many privately owned latrines, although a more typical number is $75^{\text {iv }}$. It is common belief that the Nairobi police are unwilling to patrol 
the area. Visitors are warned to beware of "flying toilets" which result at night when, out of fear of walking to the latrines, residents use polythene bags as commodes and throw them out the door or over the roof ${ }^{v}$.

The typical home is arranged to share three walls with neighbors so there is only one window and one door for lighting and ventilation. The homes are dark even during the day. In the evening, two types of kerosene burning lamps are commonly used for lighting. Shown in Figure 1 are the small koroboi and the larger "hurricane" lantern. The handful of families queried are spending about 20 Kenyan shillings per day on kerosene (about 0.28 \$US) for 2.5 hours of light. The indoor air pollution that results from the kerosene fumes and poor ventilation has been shown to contribute to a condition known as acute respiratory infection (ARI), especially in children $^{\mathrm{vi}}$. Furthermore, these lanterns are an apparent fire hazard in a place with such overcrowding and lack of emergency response capability.

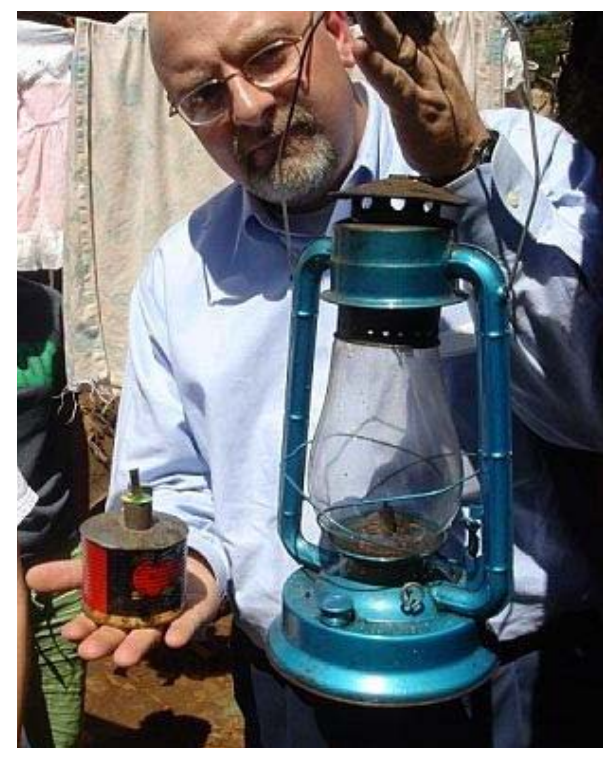

FIGURE 1

Kerosene Burning Koroboi AND Hurricane LANTERn Used In KiBERA For Lighting

\section{Objectives on Behalf of Kibera Residents:}

As described above, poor conditions exist for respiratory health, employment, and safety from fires for people living in Kibera. The kerosene-based light commonly used is of such poor quality that it affects children's academic performance, domestic productivity, and family dynamics. Electric lighting can be a solution to many of these problems simultaneously, and though less obvious to westerners, electric lights can bring a increased sense of hope for the future and self worth to people previously living without $\mathrm{it}^{\mathrm{vii}}$. Therefore, as I considered an electric lighting project, a set of project goals was established on behalf of the residents. These are to:

- Provide a task light to 20 Kibera families adequate for cooking, reading, cleaning, or performing income generating tasks such as sewing clothing or making handcrafts. 
- Use solar and/or wind power as the primary power source and deep-cycle lead acid batteries for energy storage.

- Explore the viability of the system as a small light providing business ${ }^{\text {viii }}$.

- Use white light-emitting diode (WLED) arrays instead of incandescent or fluorescent lamps for their superior efficiency in terms of lumens per watt ${ }^{\mathrm{ix}}$.

- Make use of the crowded living conditions by using transmission lines short enough to allow low voltage DC power with acceptable losses. Use low current circuit breakers to limit individual household usage. Avoid transformers and consumer metering to minimize cost and complexity, reduce electrocution dangers, and discourage tampering.

\section{Objectives for Student Participants:}

As an engineering educator, I knew that the Kibera residents would not be the only beneficiaries of the project. There was potential for significant student learning to take place, not only in the hard technical sense, but also in more intangible ways. Therefore, additional objectives for the students were established:

- Increase their respect of, and appreciation for, other cultures ${ }^{\mathrm{x}, \mathrm{xi}}$.

- Get a firsthand example of discipline-specific service that might act as a precipitant to humanitarian, development oriented, compassionate service within their professions ${ }^{\mathrm{xii}}$.

- Gain exposure to technologies that are culturally and infrastructurally appropriate, with emphasis on sustainability.

- Increase their understanding of alternative energy techniques, specifically electric power generation from wind.

- More fully illuminate the practice of engineering design by exposure to the hands-on problem solving and the adaptation to unforeseeable details.

- Apprehend the depth and breadth of African urban poverty and come to terms with their own relative wealth as westerners.

- Grow in their knowledge that people, not technologies, are the ultimate focus of engineering through socially relevant projects ${ }^{x i i i}$ This aids in the retention and motivation of female students in particular ${ }^{\text {xiv }}$.

\section{Project Description}

\section{Choice of Site, Partners, and Energy Source:}

As part of the engineering educational process, students were involved in the project's conceptual development and selection of key suppliers. In this way they gained first hand knowledge of how such projects are conceived, grow, and evolve. This section describes that process.

The project was first considered a year prior to implementation with members of Practical Action (formerly Intermediate Technology Development Group, ITDG) ${ }^{\mathrm{xv}}$ which proved to be a key partner in the endeavor because of their prior work in Kibera. Practical Action has designed and built several successful latrine and shower facilities in Kibera that allow the owning 
organizations to collect fees to provide for the maintenance and upkeep of the system, and pay a wage to employees. The systems are financially sustainable.

As power sources were discussed with Practical Action, the intense equatorial radiation of Nairobi made solar energy a natural consideration, but the high crime rate in Kibera and lucrative black market resale value of solar panels made us consider other alternatives. Wind power is less expensive per kilowatt-hour than solar photovoltaics, and there seems to be less theft of wind generators than solar panels ${ }^{\mathrm{xvi}}$. Furthermore, the rarity of wind impediments such as trees or multistory buildings in Kibera seemed promising in regards to wind conditions. Therefore wind power was made the first choice, solar the second.

When possible, local materials were preferred so that the system could be more easily replicated. An internet search uncovered the company CraftSkills ${ }^{\text {xvii }}$ making technologically appropriate wind generators, often from scrap materials, and providentially located on the edge of Kibera itself. Thus, the supplier was chosen based on proximity to the project site. One of the latrine facilities built by Practical Action was located in the "village" of Kianda, a large subdivision within Kibera a short walking distance from CraftSkills. Within Kianda, a community group known as Umoja Maendeleo na Maisha Kianda (UMMK), meaning the "Federation for the Development of Life in Kianda," is the owner and operator of this latrine and shower. A cinderblock building was designed and built by Practical Action to house it while the UMMK provides administration of the project, collecting the fees, keeping it clean, and providing a measure of security through unarmed and unpaid security guards.

This latrine facility proved to be the best available choice for the location of the project because of its location, the existence and cooperation of the UMMK as an owning organization, the proximity to the wind generator manufacturer, and the preexistence of a building to house battery charging equipment. This location was not without drawbacks, however. The lack of available land for the 30 foot tower and the need for security forced us to locate the tower closer to the two story latrine building than would have been optimal for wind conditions. Thus, the students were provided an example of how design engineering is often a compromise between competing requirements, not all of which are technical. Figure 2 shows the students, the tower, and the latrine building.

A final partner for this project was found at the Jomo Kenyatta University of Agriculture and Technology Institute of Energy and Environmental Technology. Graduate students working in renewable energy systems were enlisted to perform periodic system checks including keeping battery voltage logs.

\section{System Level Design:}

The system is illustrated by the block diagram shown in Figure 3a. In summary, 3-phase AC power from a wind generator is regulated by a charge controller to charge the single, deep cycle battery housed in a central location. Power from this battery is distributed through a circuit breaker box with a single master circuit breaker and 20 thermal circuit breakers rated at $1 \mathrm{~A}$ each that control the power used by each individual home. Figure 4 shows the circuit breaker box, battery, and charge controller circuitry which are housed in a locked storage room of the latrine building.

In addition to the efforts of the seven participating students, some system components were designed by members of the student organization Engineers with a Mission ${ }^{\text {xviii }}$, a student group at Baylor dedicated to using appropriate technologies to serve the poor of developing 
countries. These components include a circuit breaker panel, and WLED arrays for light sources.

Two-conductor, number 16 American Wire Gage (AWG), outdoor extension cords were used to route power from the circuit breaker box to the individual homes. Cords of different lengths were coded by different colors: orange for 50 feet, yellow for 80 feet, and lime green for 120 feet. While originally designed for high visibility and lawn safety, the bright colors were an aid to routing and installation, and a source of amused perplexity to the residents.

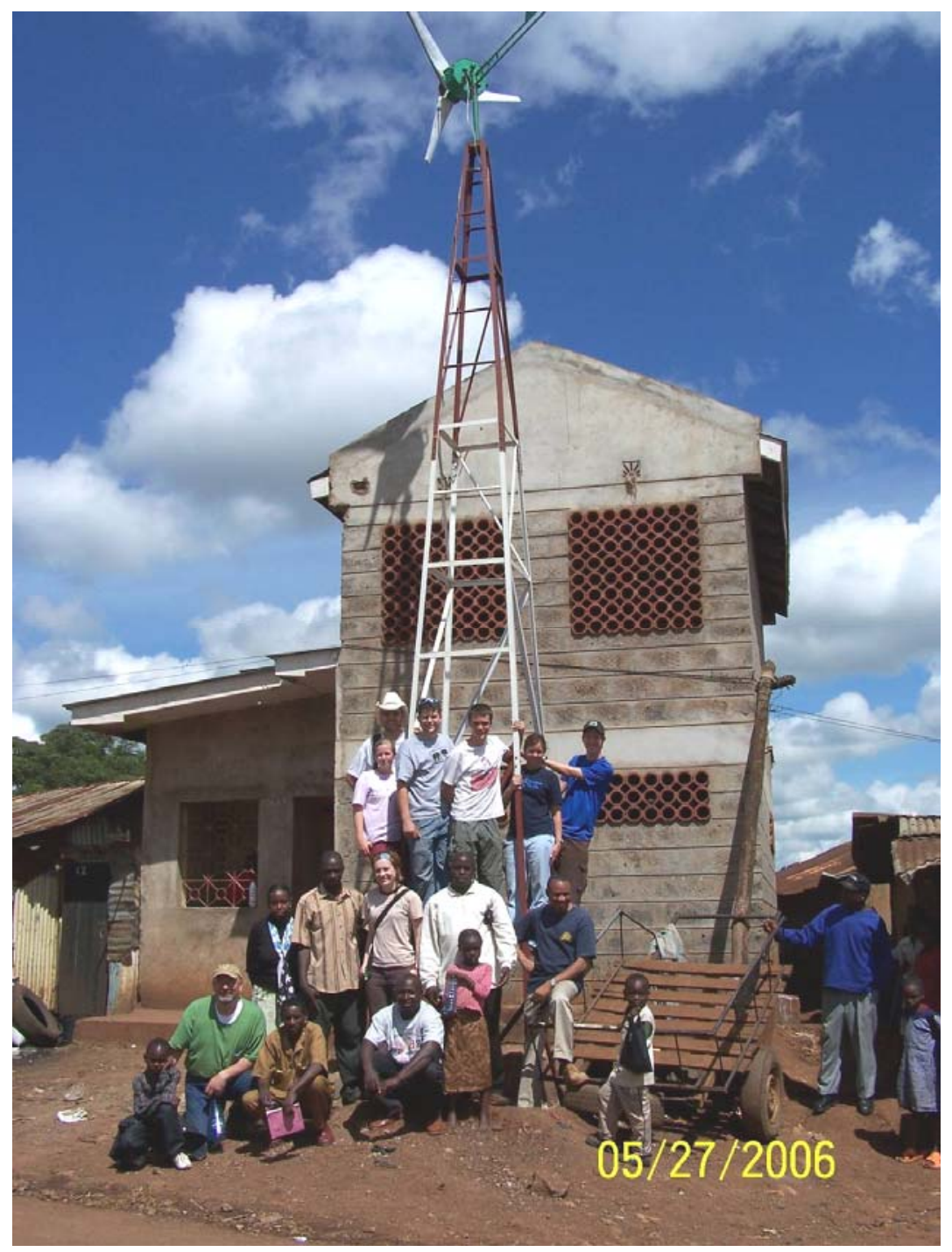

FIGURE 2

STUDENTS AND LOCAL PARTNERS WITH WIND GENERATOR, 30 FOOT TOWER, AND LATRINE FACILITY IN REAR

The male and female ends of the extension cords formed the light switches for cost savings and reliability. This was achieved by cutting the cords about three feet from the male end, and soldering the exposed wires into the WLED arrays. The arrays then had a short "tail" that could be plugged into the female end at the individual homes. The arrays and their male-end cords are 
shown in Figure $3 \mathrm{~b}$. The balance of the female ended cord ran from the home to the circuit breaker box for connection. This switching scheme is not shown in the schematic of Figure 3a for clarity. It should be noted that while the engineers thought this switching solution was elegant, the Kenyans did not seem impressed and may have thought it crude.

Also shown in Figures $3 \mathrm{a}$ and 4, are automotive adaptors to charge cellular telephones, as they are common even in Kibera. These were included in the system in hopes of generating another income stream for the UMMK from cellular battery charging fees, as well as increasing the security of residents by aiding communication.

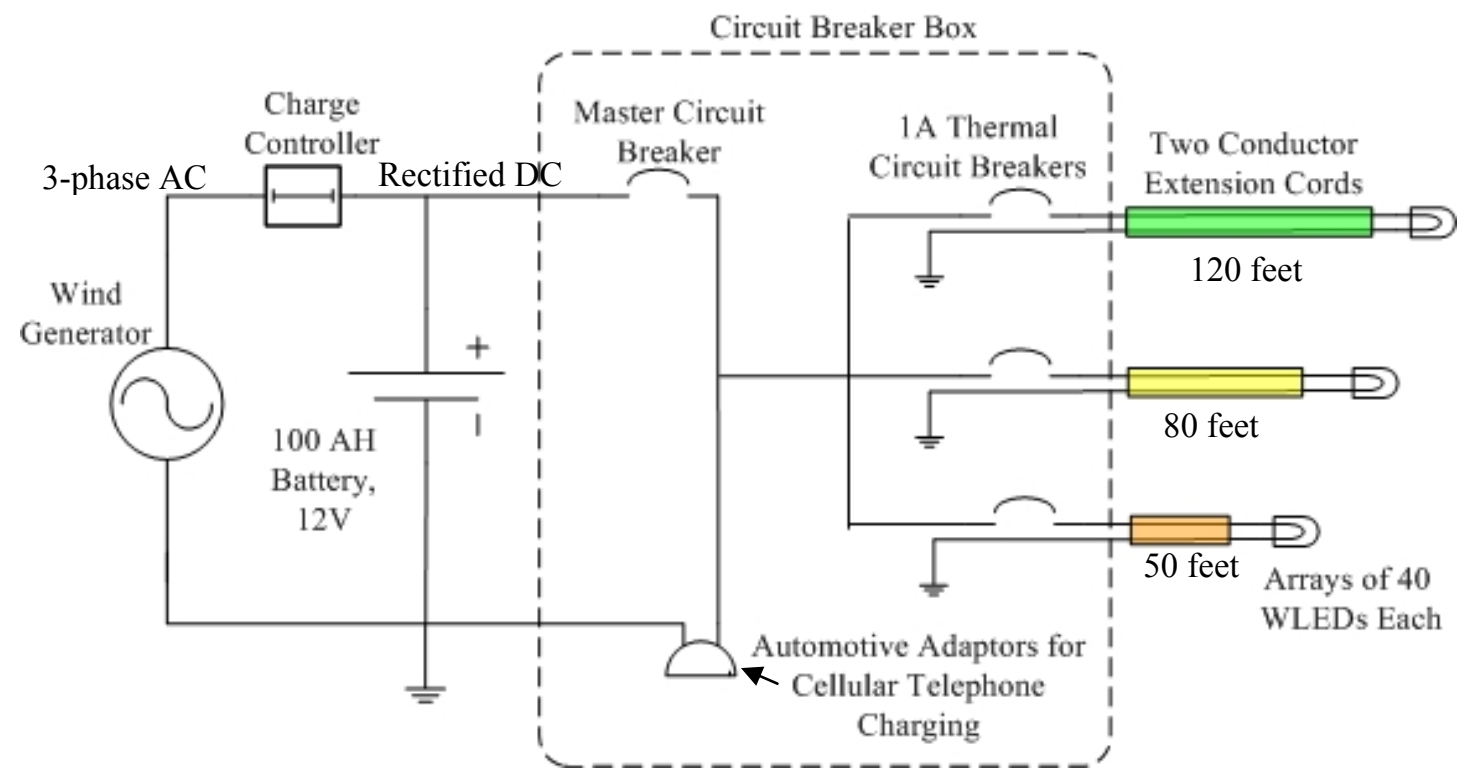

FIGURE 3A

SYSTEM LEVEL BLOCK DIAGRAM

(SOME DUPLICATE COMPONETS REMOVED FOR CLARITY)

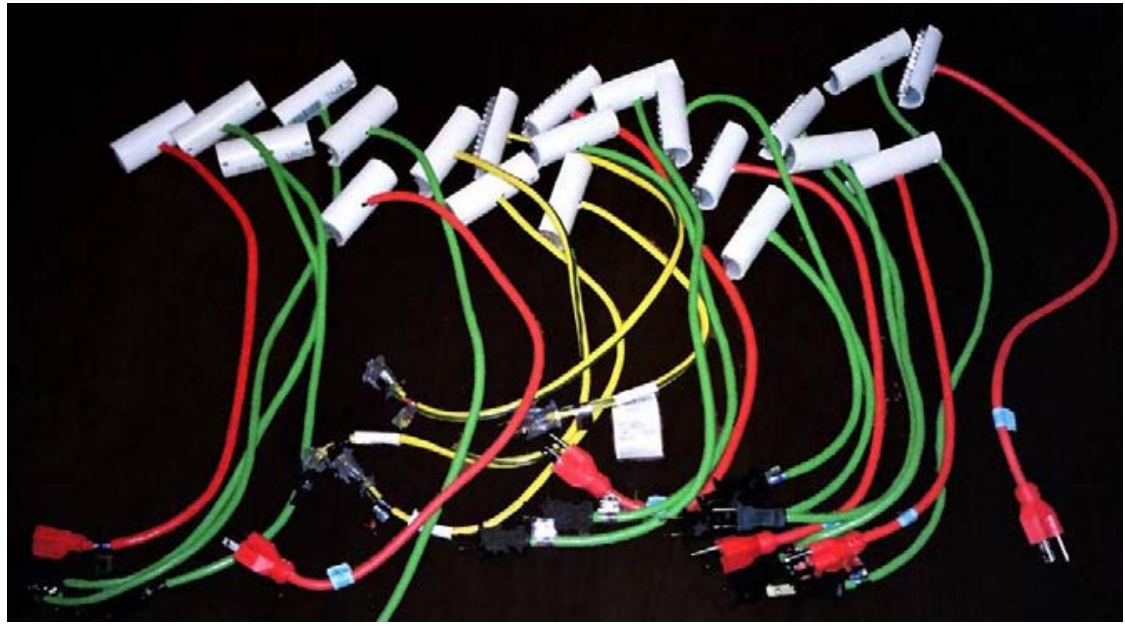

FIGURE 3B

TAsk Lights: WLED ARrays With Male Plugs Cut From Extension Cords 


\section{WLED Task Light Design:}

For the task light design, 40 WLED's were arranged into an array so that all their light was directed in one direction. The WLED's were rated at 10,000 mcd each and had a nominal voltage drop of $3.5 \mathrm{~V}$. No biasing resistors were used to avoid resistive power losses and thus maximize power conversion into light. This was accomplished by arranging four WLED's in series so that a battery voltage of 12-14 V would produce a 3.0-3.5 V drop across each WLED. Ten such strings were connected in parallel as shown in Figure 5. In an effort to keep the design simple and inexpensive, the WLED's were soldered into a perfboard and housed in a section of one inch PVC pipe, cut lengthwise and filled with silicone sealant to weatherproof it and keep out insects. Figure 6 shows photographs of a prototype.

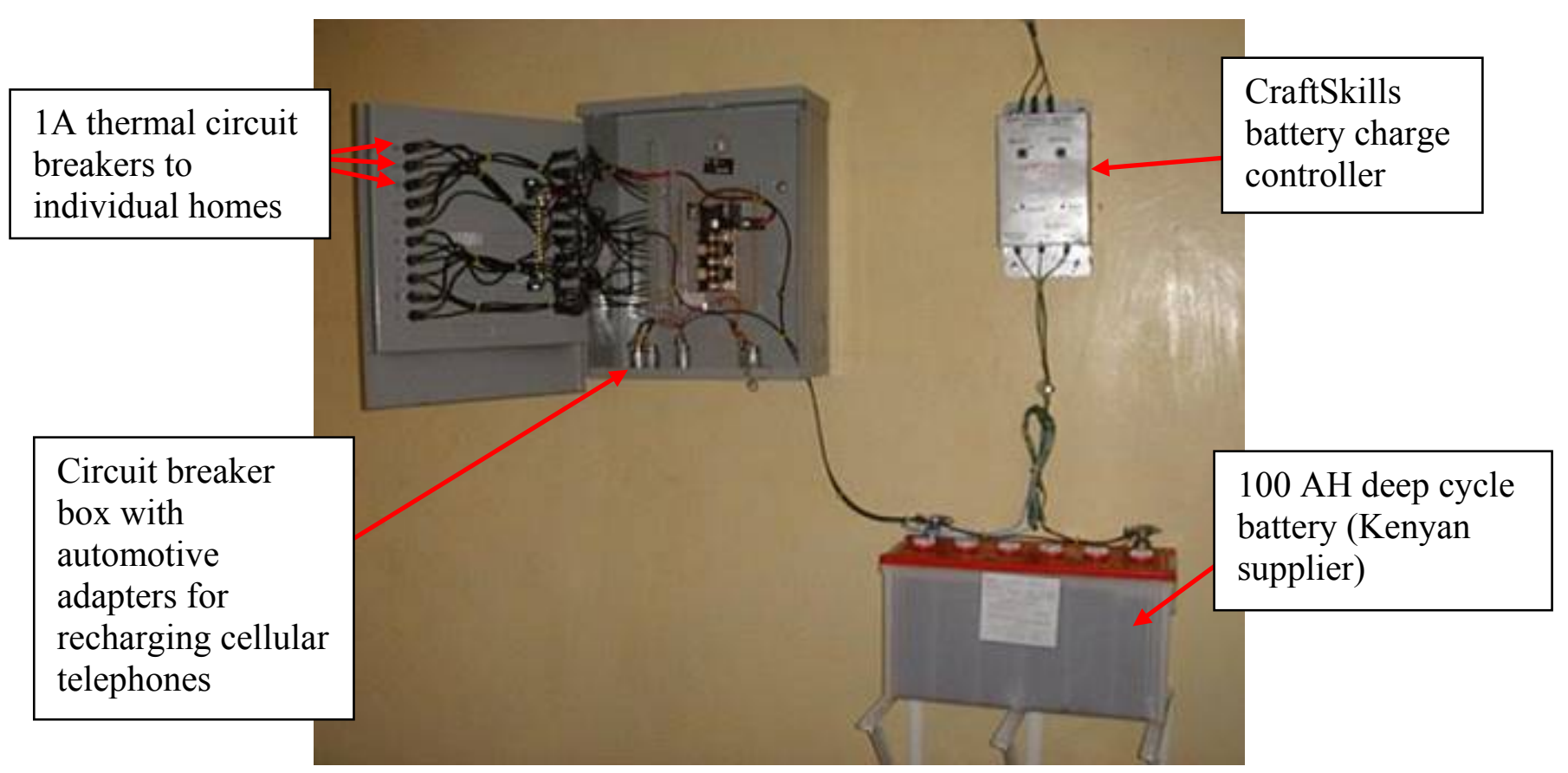

FIGURE 4

Circuit Breaker Box, Charge Controller, AND BATtery

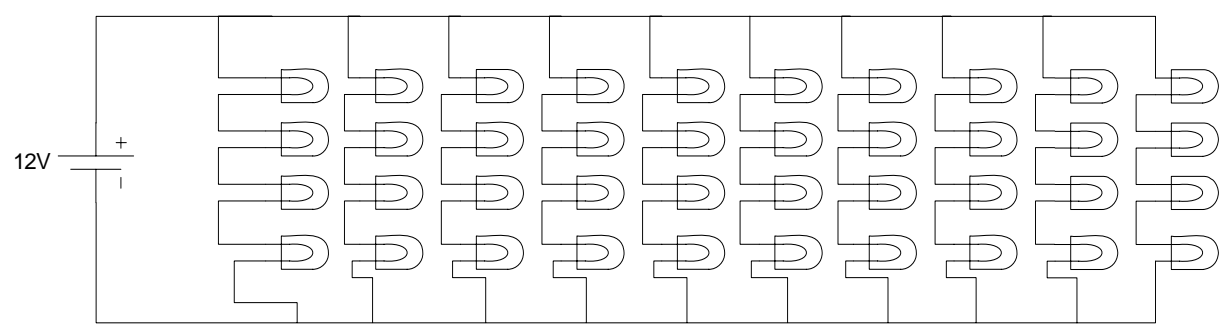

FigURE 5

SCHEMATIC OF WHITE LED ARRAY 
The illuminance pattern of a prototype WLED array was tested using a laboratory power supply and photographer's illuminance meter. The WLED array was hung from the ceiling in a dark room, 70 inches above a table top. Using the meter, the point of maximum illuminance was found and defined to be the nadir, an astronomical term meaning the opposite of the zenith. The meter was moved in a straight line in six inch increments away from the nadir and illuminance was measured at each point as shown in Figure 7. At each point the illuminance was recorded in units of lux, or lumens per square meter. This test was also performed with a high-efficiency, 12 $\mathrm{W}, 12 \mathrm{~V}$ fluorescent bulb for comparison. The results are shown in Figures 8, 9, and 10. The data support the design intent that this light would be best suited for performing a specific task such as reading, cooking, or sewing.

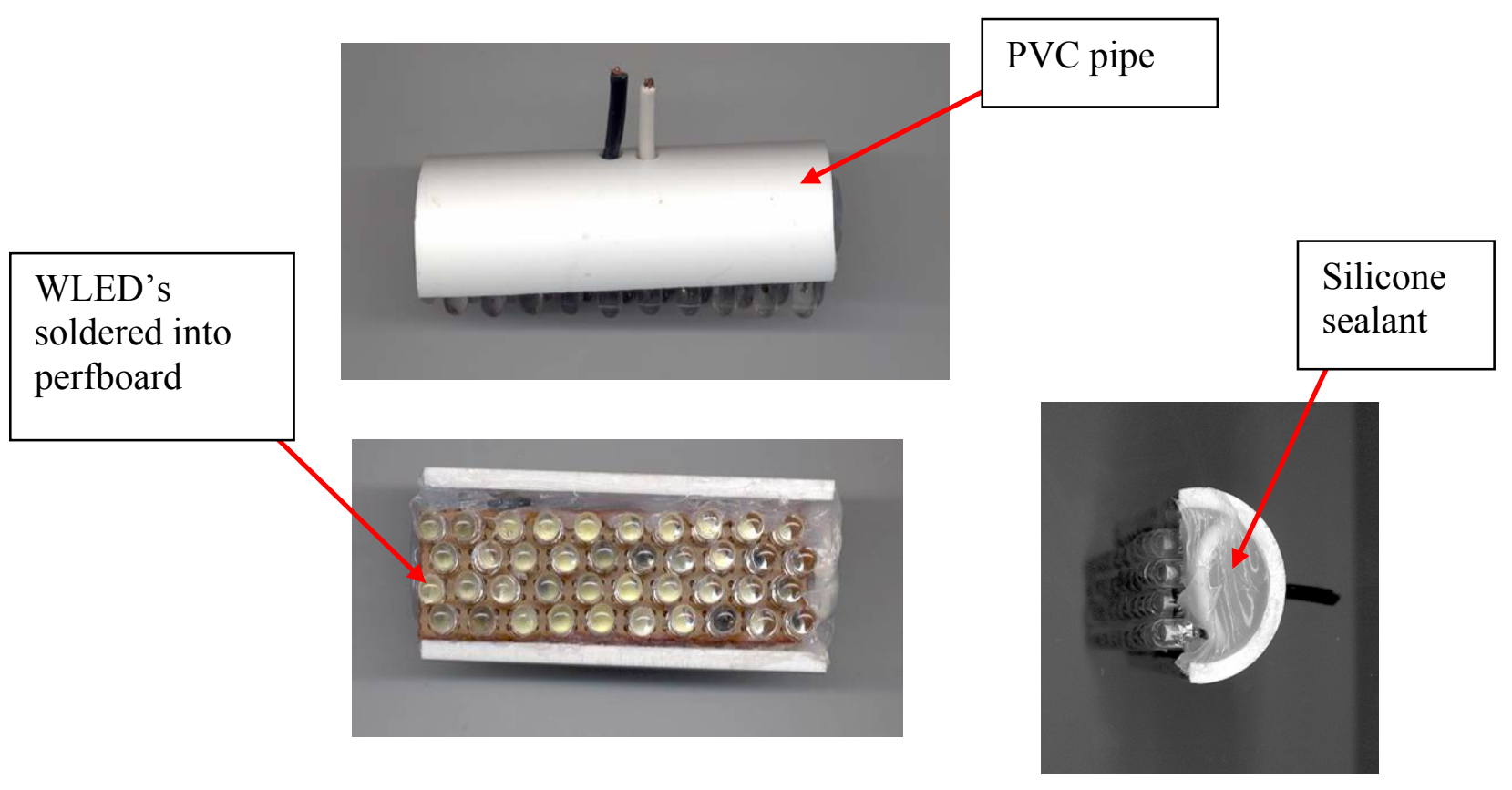

\section{FIGURE 6 \\ WLED ARRAY CONSTRUCTION}

Line losses were found experimentally to be about $0.5 \mathrm{~V}$ for the maximum battery voltage of 14.0 $\mathrm{V}$ when using the longest extension cord of 120 feet. Figure 9 shows the power consumed as a function of array terminal voltage. When performing the measurements for Figure 9, a mistake was made by not recording data beyond $13.5 \mathrm{~V}$. While this would have been acceptable if all the extension cords were 120 feet, some were shorter and would have shown less loss, so that a $14.0 \mathrm{~V}$ battery with a short line length might see an estimated array terminal voltage of $13.8 \mathrm{~V}$. 


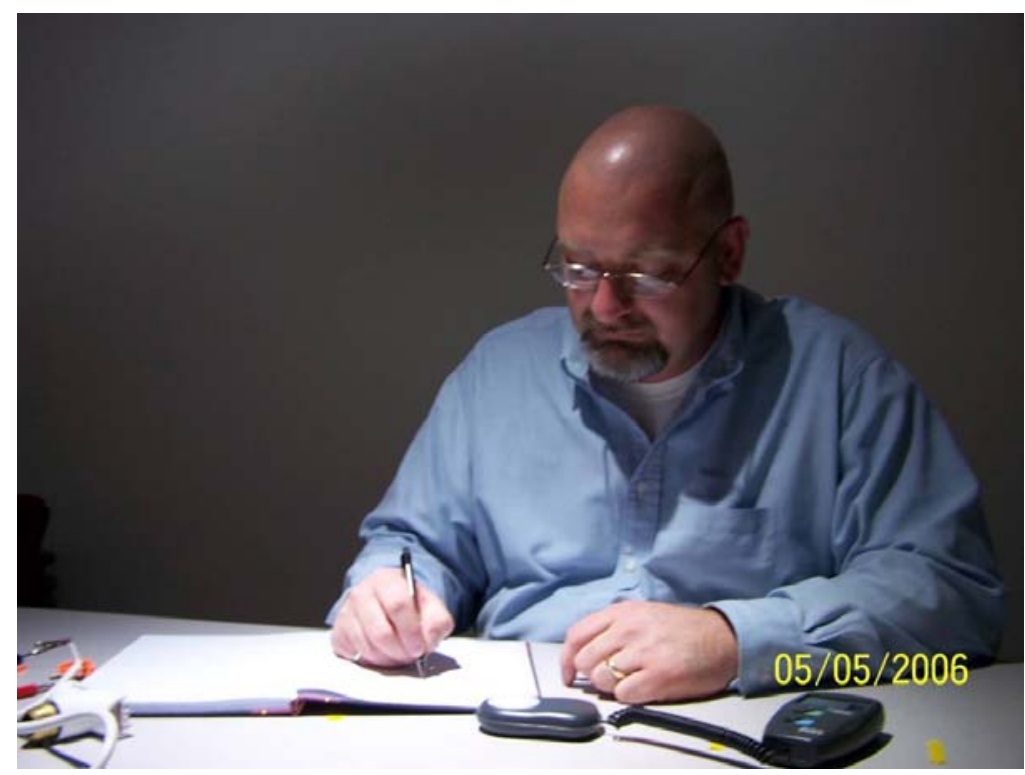

FIGURE 7

ILLUMINANCE AND DIRECTIVITY TESTING OF WLED ARRAY USING PHOTOGRAPHER's ILLUMINANCE METER MEASURING LUX

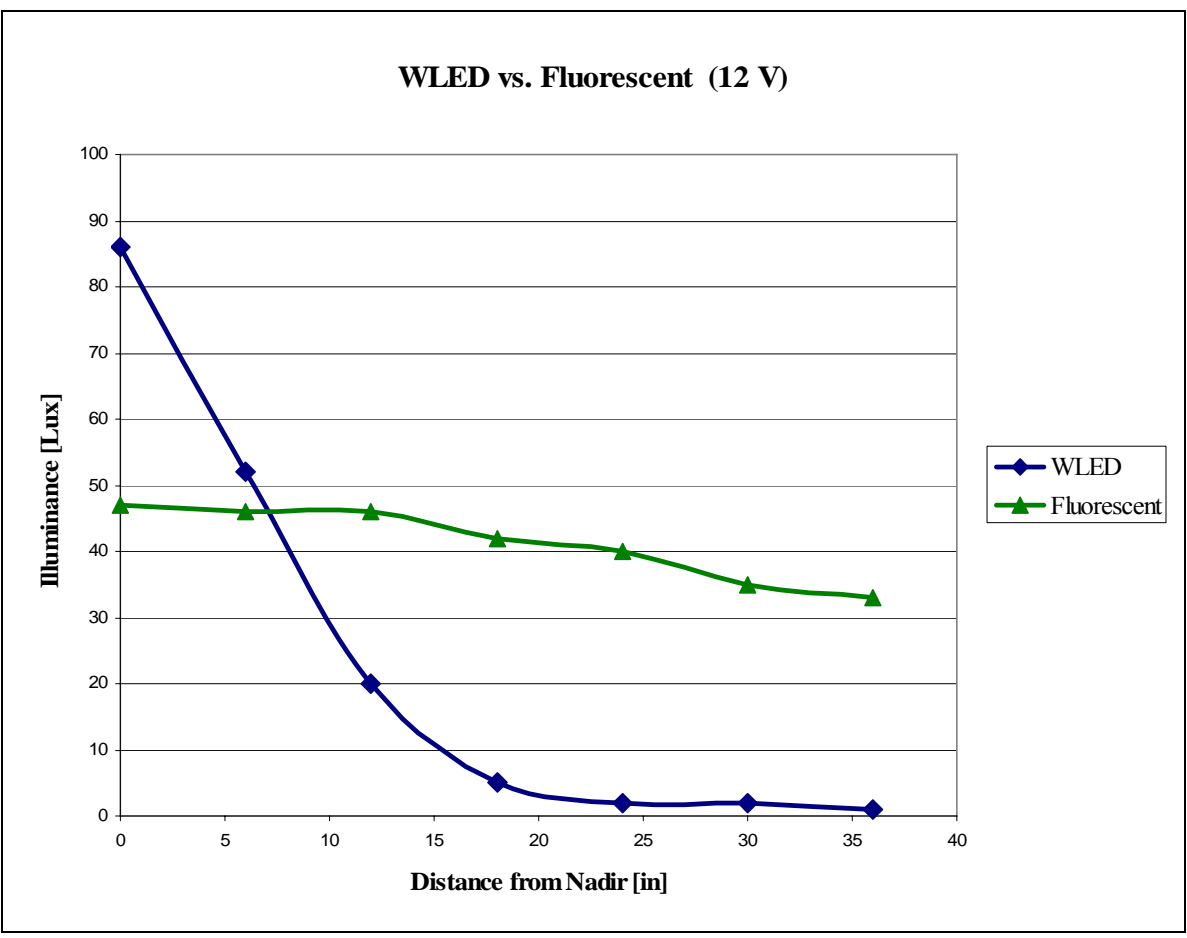

FIGURE 8

ILLUMINANCE PATTERN TESTING OF WLED ARRAY AND

FLUORESCENT LAMP COMPARISON 


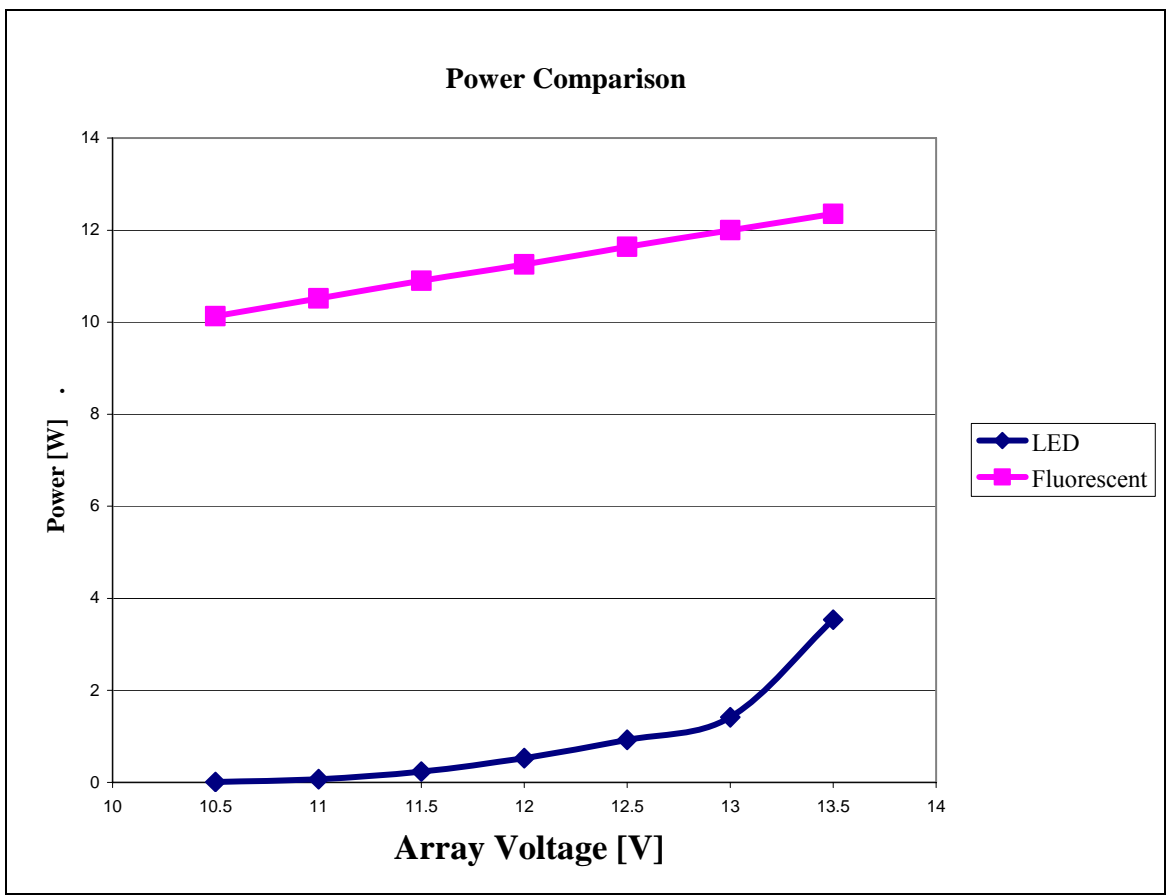

FIGURE 9

Power Usage Vs. ARray VOLTAGE FOr WLED AND FLUORESCENT

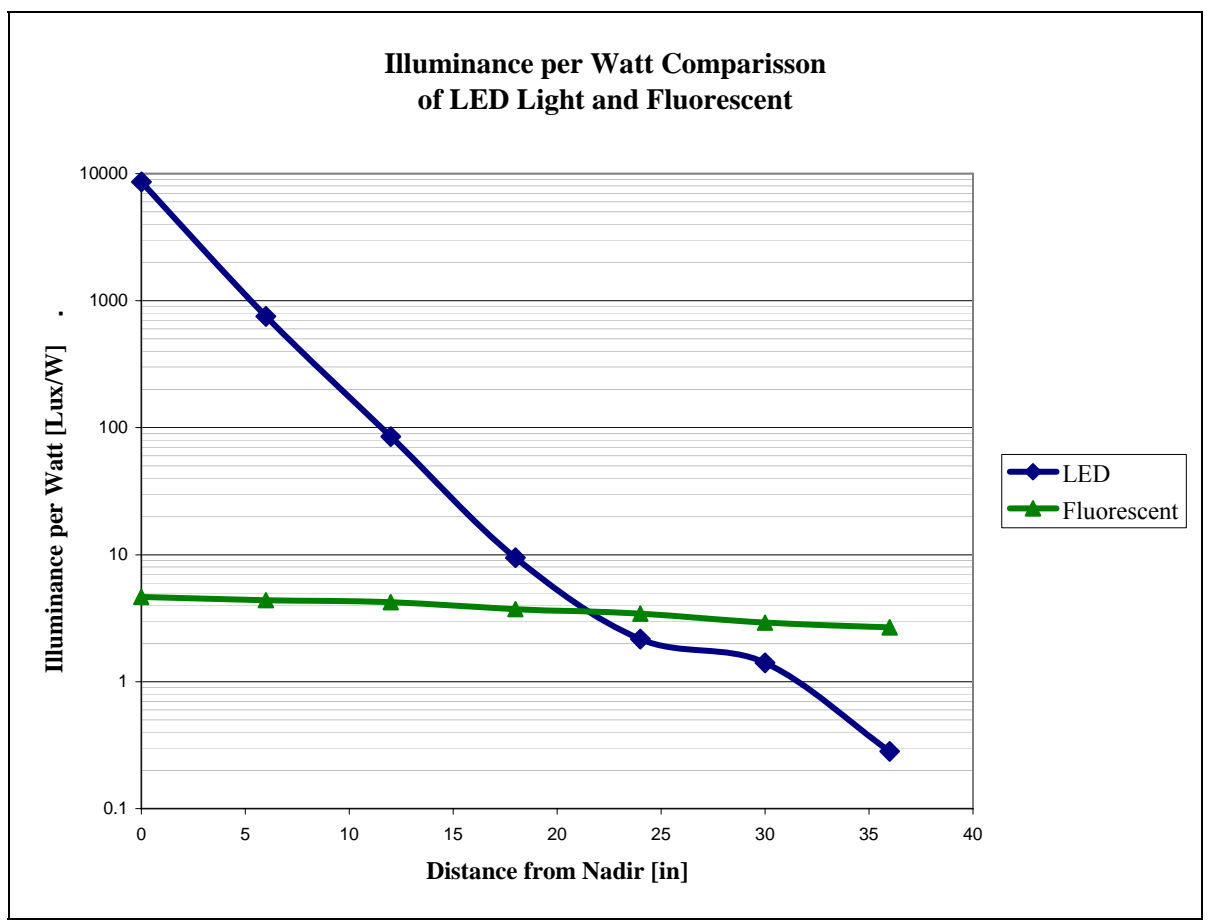

FIGURE 10

ILLUMINANCE PER WATT FOR WLED AND FLUORESCENT COMPARISON LAMP 


\section{Power Budget:}

Assuming the average battery voltage is $13.5 \mathrm{~V}$, and further assuming the typical line losses are an additional $0.5 \mathrm{~V}$, Figure 9 shows each array will consume about $1.5 \mathrm{~W}$ at a $13.0 \mathrm{~V}$ operational voltage. A total of 20 arrays, and an average usage of 5 hours per day requires energy provided by the battery to be $20 \cdot 1.5 \mathrm{~W} \cdot 5 \mathrm{hr}=150 \mathrm{Whr}$.

Assuming an battery charge and discharge efficiency of 0.8 , typical of lead acid batteries, then the wind generator must produce $150 \mathrm{Whr} / 0.8=188 \mathrm{Whr}$ daily. Therefore the selected generator rated at $300 \mathrm{~W}$ peak needs only to produce $47 \mathrm{~W}$ for 4 hours, for example. Detailed estimates of the wind conditions such as mean wind speed or the Weibull distribution shape factor were not known for the site, nor was a power curve relating output power to wind speed for the generator. Despite these unknowns, the power budget seemed conservative since it required only 4 hours at $47 \mathrm{~W} / 300 \mathrm{~W} \approx 16 \%$ of the turbine's rated output power. The battery rated at $100 \mathrm{Ahr}$, or $1200 \mathrm{Whr}$, would only see a $188 \mathrm{Whr} / 1200 \mathrm{Whr} \approx 16 \%$ depth of discharge daily. This limit is well within manufacturer's recommendations, as deep cycle batteries may often operate beyond $50 \%$ depth of discharge.

\section{Equipment Costs:}

Table I lists the equipment costs associated with the project. Costs have been converted to US dollars at a rate of 70 Kenyan shillings per dollar. The cost of the individual WLED arrays is about \$9 USD each, excluding the extension cords. Most of this cost is from the 40 WLED's which were purchased for \$0.20 USD per unit directly from a Hong Kong based manufacturer using eBay ${ }^{\circledR}$. The manufacturing labor was volunteered by Engineers with a Mission students, keeping costs down and adding to the learning experience. The additional cost of an $80 \mathrm{~W}$ solar photovoltaic panel has been added into the total, the reason for which is given in the Conclusions section. A budget of $\$ 2,300$ USD was raised through private donations, but was exceeded because of the solar panel.

\section{CONCLUSIONS AND REFLECTIONS}

This project had objectives for both the Kibera residents and the student participants. In regards to the Kenyan residents, all of the stated objectives were met with two exceptions. Instead of 20 homes, only 17 were able to be lit. This is due to an uncooperative landlord that refused to allow the installation of lights in his rental properties because he feared the fire hazard. The kerosene lamps the system would be replacing were, in his view, less of a danger. Therefore the radial transmission line pattern desired had to be elongated and distorted to the point that in order to reach additional homes, longer lines with unacceptable voltage drops approaching one volt would have been required. Therefore, the remaining three circuits and WLED arrays were used to illuminate the latrine building, including providing light for a community room where children could come to work on school assignments.

The second unmet goal which remains an area for further work is the exploration of the viability of the system as a light producing business. A fee collection system was discussed with UMMK, and working together a weekly fee of \$0.45 USD was established. This was considered to be affordable by the residents since they were now spending \$0.28 USD daily on kerosene. At this rate, nearly $\$ 400$ USD per year could be collected to maintain the system. 
A serious problem of unusually calm winds occurred shortly after installation in June and July. This resulted in the battery being discharged too deeply and the lights ceasing to function.

A contingency plan of installing a solar photovoltaic panel was instigated and an $80 \mathrm{~W}$ panel was installed in conjunction with the wind generator. This solution had been avoided because of theft and cost issues, but proved necessary for the low-wind months. At the time of this writing, it has been in place for ten months without being stolen, as was feared. Unfortunately, before the solar panel could be installed, the battery sat in a discharged state for several weeks, suffering permanent damage through sulfation, diminishing its capacity significantly.

In retrospect, the team should have installed an automatic shut off feature to disconnect the load when the battery voltage fell below a minimum threshold. The UMMK operators received instruction to do this manually using a hand held voltmeter supplied by researchers at Jomo Kenyatta University, but it may not have been actually used.

Considering this system as a small business, the question arises, is it market deployable through micro financing or, if not, is it at least market sustainable if the installation costs are provided through donors or charities? Because of the inconsistencies of operation, the collection of fees has been insufficient and sporadic to the extent that the answer to the questions of financial viability are unknown. The addition of the solar panel required a budgetary overrun of nearly $30 \%$ and is a step away from in-country manufacturability. If the requirement that the system function twelve months per year could be relaxed to only windy months, the solar panel could likely be avoided.

There also seems to be a cultural obstacle. Despite the fact that only the homes lit by the project would be paying the fees, the UMMK is reluctant to purchase a new battery for the system because it does not serve the entire community. The UMMK was formed to serve all of Kianda, not just the seventeen homes that were lit by this project. The community mindedness of Kenyan culture, of which this is an example, comes as a surprise to western students, though its virtues are respected once understood.

\section{Post-Trip Student Surveys:}

In effort to assess the impact on students in the areas of the stated objectives, I sent an anonymous survey to all participants via email. After completing the surveys, the students returned them to a third party who stripped them of identifying markers. Students were asked to read a statement and indicate whether they strongly agreed, agreed, were neutral, disagreed, or strongly disagreed with it. The results of this survey are given in Table II. Furthermore, students were given a list of skills and asked to indicate which improved during their trip. These results are given in Table III.

The survey data indicates that most of the stated objectives were met successfully. In particular, objectives concerning service, appropriate technologies, alternative energy, poverty apprehension, and the social relevance of engineering were strongly met. The objective of more fully illuminating the practice of engineering design was met with less success. This may be in part due to the diversity of student ability. Of the seven students on the team, three had completed only one year of undergraduate studies, one had completed two years, one three years, and two had completed four years but not yet graduated. The advanced students had more prior exposure to engineering design and more developed technical skills. This influenced their ability to contribute to the overall project and hence grow in their understanding of design. The objectives not associated with engineering design such as understanding global issues, however, 
were met more uniformly, perhaps in part due to the students having less exposure to these topics in the engineering academic curriculum.

TABLE I

EQUIPMENT COSTS

\begin{tabular}{|clcc|}
\hline Date & \multicolumn{1}{c}{ Description } & Ksh & $\$$ US \\
1-Apr & WLED, 10,000 mcd, 1000 pcs. & & $\$ 200.00$ \\
20-Apr & CraftSkills Items & & \\
& 300 W generator & 33000 & $\$ 468.09$ \\
& Fiberglass blades & 5200 & $\$ 73.76$ \\
& charge controller & 4500 & $\$ 63.83$ \\
& power cable & 2500 & $\$ 35.46$ \\
& 30 ft. tower & 15000 & $\$ 212.77$ \\
& installation charges & 20910 & $\$ 296.60$ \\
25-Apr & 4, 80 foot extension cords at $\$ 11.34$ each & & $\$ 45.36$ \\
25-Apr & 6, 50 foot extension corsd at $\$ 6.17$ each & & $\$ 37.02$ \\
25-Apr & 12, 120 foot extension corrds at $\$ 11.34$ & & $\$ 136.08$ \\
25-Apr & 3, rubber caulk at $\$ 4.86$ each & & $\$ 14.58$ \\
25-Apr & wire stripper tool & & $\$ 14.66$ \\
25-Apr & circuit breaker box & & $\$ 90.00$ \\
25-Apr & 30 A master breaker & & $\$ 5.00$ \\
25-Apr & 20,1A thermal circuit breakers & & $\$ 140.00$ \\
25-Apr & 12 AWG stranded copper wire & & $\$ 20.00$ \\
25-Apr & 5, auto plug adapters & & $\$ 15.00$ \\
25-Apr & 1 inch PVC pipe, 10 foot length & & $\$ 3.12$ \\
25-Apr & duct tape & & $\$ 2.97$ \\
18-May & 100 AH, deep cycle battery & 9500 & $\$ 134.75$ \\
19-May & padlock & 1030 & $\$ 14.61$ \\
19-May & wall plugs, brackets, hand drill & 3670 & $\$ 52.06$ \\
20-May & cable ties & 1395 & $\$ 19.79$ \\
26-May & tips for technicians & 300 & $\$ 4.26$ \\
26-May & tips for security guards & 4000 & $\$ 56.74$ \\
10-Jul & solar panel & & $\$ 643.00$ \\
& & TOTAL: & $\$ 2,799.49$ \\
\hline
\end{tabular}

One objective, that of increasing the respect of, and appreciation for, other cultures, had mixed results. Survey questions involving foreign language scored poorly, while sensitivity to different cultures, global issues, and interest in world events and social issues scored strongly. This might be attributable to the fact that English is spoken by many in Kenya, so the cultural experience was rich, but the need for another language was minimal. Figure 11 illustrates a moment of cultural richness as one of the students walked past a wall mural depicting life in Kibera through the eyes of a resident. The sign reads "Haus 2 Let, Bedloom, Sit in, Kichen, all under 1 roof, Kibera" satirically reflecting life in the single room dwellings. 
TABLE II

POST-TRIP STUDENT SURVEY SUMMARY

\begin{tabular}{|l|c|c|c|}
\hline \multicolumn{1}{|c|}{ Question } & $\begin{array}{c}\% \text { that } \\
\text { Strongly } \\
\text { Agree (SA) }\end{array}$ & $\begin{array}{c}\text { \% that } \\
\text { Agree } \\
\text { (A) }\end{array}$ & $\begin{array}{c}\text { \% Neutral } \\
\text { (N), (D), or } \\
\text { (SD) }\end{array}$ \\
\hline Increased my understanding of engineering design & $60 \%$ & $40 \%$ & $0 \%$ \\
\hline Increased my interest in engineering as service & $60 \%$ & $40 \%$ & $0 \%$ \\
\hline Altered my perception of wealth and poverty & $100 \%$ & $0 \%$ & $0 \%$ \\
\hline Increased my interest in appropriate technology & $100 \%$ & $0 \%$ & $0 \%$ \\
\hline Increased my interest in alternative energy & $60 \%$ & $40 \%$ & $0 \%$ \\
\hline $\begin{array}{l}\text { Increased my appreciation for the cultural elements of } \\
\text { engineering design }\end{array}$ & $80 \%$ & $20 \%$ & $0 \%$ \\
\hline Helped my see how engineering projects can be socially relevant & $80 \%$ & $20 \%$ & $0 \%$ \\
\hline Improved my foreign language skills & $20 \%$ & $0 \%$ & $80 \%$ \\
\hline Increased my appreciation for study of foreign language & $0 \%$ & $20 \%$ & $80 \%$ \\
\hline $\begin{array}{l}\text { Resulted in a more positive view of my host country and its } \\
\text { people }\end{array}$ & $20 \%$ & $40 \%$ & $40 \%$ \\
\hline
\end{tabular}

TABLE III

AdDitional Post-Trip STUdENT SURVEY SUMMARY

\begin{tabular}{|l|c|}
\hline Skill & \% indicating improvement \\
\hline Openness & $100 \%$ \\
\hline Self-awareness & $60 \%$ \\
\hline Ability to work in groups & $60 \%$ \\
\hline Understanding of global issues & $100 \%$ \\
\hline Foreign language skills & $40 \%$ \\
\hline Interest in world events and social issues & $80 \%$ \\
\hline Receptivity to different ways of thinking & $80 \%$ \\
\hline Sensitivity to different cultures & $100 \%$ \\
\hline
\end{tabular}

Finally, some students have written summative thoughts on their trip. One such student, Amy Bowen, has since graduated and is now employed by the National Renewable Energy Lab in Colorado, U.S.A.. She writes:

"The most immediately obvious way that the trip impacted me was exposure to the value of renewable energy technology in the developing world. It was my first experience with real poverty and ... I realized that I wanted to devote some real time to that issue in the future. I realized the positive effects that energy can have on poverty and disease. Lighting provides an opportunity for people to read and work outside of daylight hours, which in turn provides them with a greater opportunity to progress educationally and financially."

In summary, the team of engineering students had an experience that is likely to alter their lives and careers and has therefore been an enriching part of their engineering education. From the early planning stages in 2005, through the design, testing, and fabrication of the WLED arrays, to the deployment in Kenya, the students were heavily involved in the decision making processes and hands-on work. Many of the stated objectives for the student participants were met, as indicated by the student surveys. Additionally, many of the objectives for the Kiberan residents were met, although the system is not without problems. 


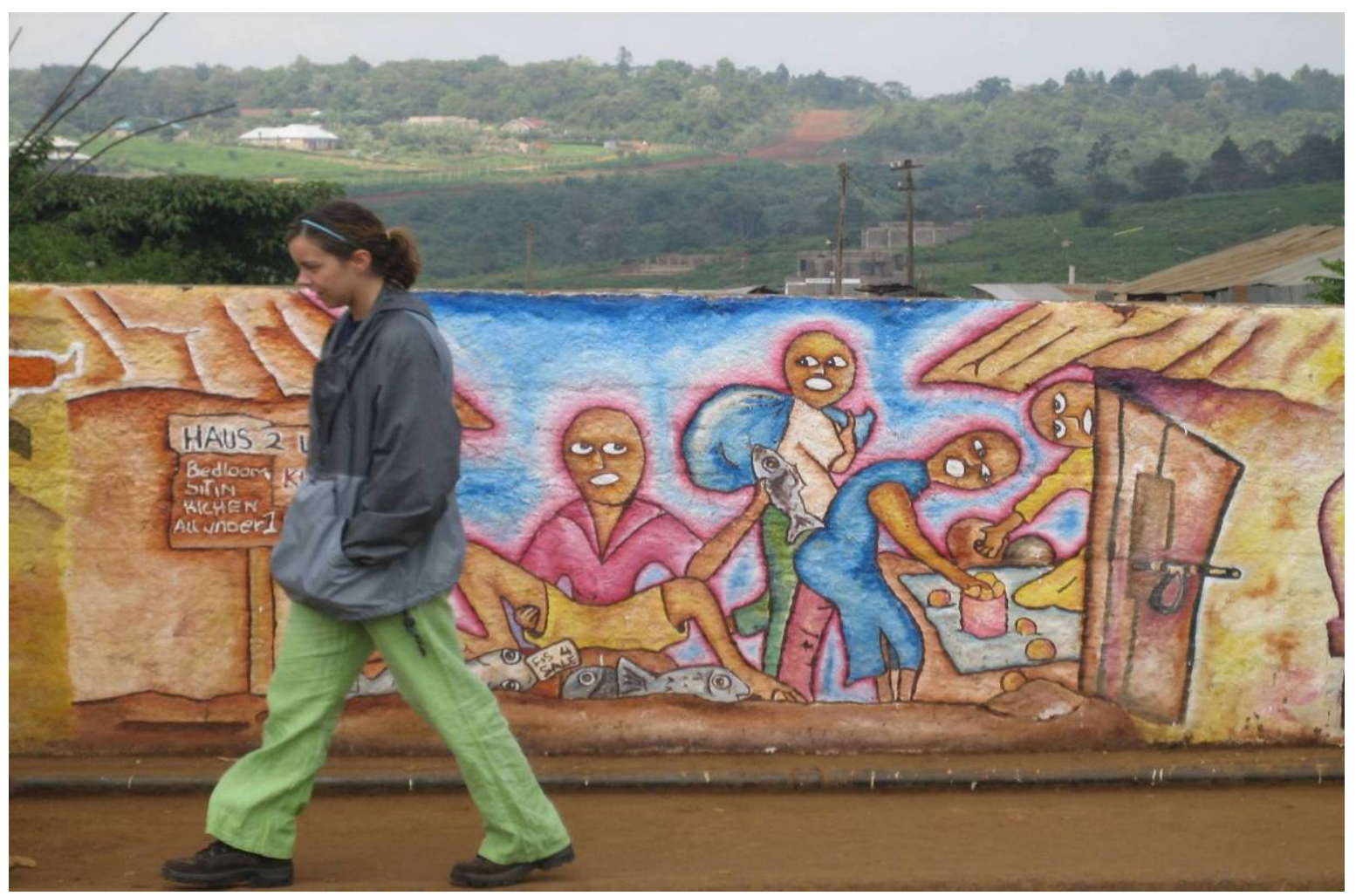

FIGURE 11

A Moment of Cultural Richness

The partners in this endeavor are: the author of this paper and student participants at Baylor University, researchers at Jomo Kenyatta University, Practical Action, and the Kianda community group UMMK. At the time of this writing, work is being done among these partners to determine the best way to proceed with the project, and to determine the technical and fiscal parameters over which the system can be sustainedly replicated.

\footnotetext{
i The use of the word "slum" carries derogatory emotional and historical connotations. The author intends no association, however, with racial, ethnic, or other personal attributes, with the warm people of Kibera. This word is used by residents and development workers alike to describe the area. In this document, the use of the word "slum" will correspond to the definition "A heavily populated urban area characterized by substandard housing and squalor" as in the American Heritage Dictionary of the English Language, Fourth Edition, by Houghton Mifflin Company, 2006.

ii Benjamin Kelley, Walter Bradley, J. Brian Thomas, "Student-Aimed Appropriate Technology Engineering Projects in Kenya", presented at the ASEE GSW Annual Conference, March 17, 2006, Baton Rouge, La. and in: Proceedings of the 2006 American Society for Engineering Education Gulf Southwest Annual Conference, 10; 2006.

iii Benson Karanja, "Electricity from Wind for the Poor", unpublished internal document of Intermediate Technology Development Group, East Africa office, Nairobi, 2005.

iv "Kibera Social and Economic Mapping: Household Survey Report, GoK/UNHABITAT, RI/4733", Research International, Ltd., Nairobi, 8.

${ }^{\vee}$ Benson Karanja, "Electricity from Wind for the Poor", unpublished internal document of Intermediate Technology Development Group, East Africa office, Nairobi, 2005.
} 
${ }^{\text {vi }}$ DN Sikolia, "The Prevalence of acute respiratory infections and the associated risk factors: A Study of children under five years of age in Kibera Lindi Village, Nairobi, Kenya," Japanese National Institute of Public Health, 51 (1): 2002

vii Based on conversations with Nathan Chesang, Kenyan Director of Servanthood \& Light Development Foundation, Kitale, Kenya, 2005-2006, http://www.light4africa.org/.

viii Bobby Brock, Michael Gallimore, Rhett Herron, "World of Light, Providing Lights to the World's Underprivileged" awarded the John Hoover Award in the Global Social Entrepreneurship Competition sponsored by the University of Washington Business School, for a business plan to provide Kibera residents with electric lights using WLED's and wind power. Mr. Brock was a participant in the Baylor trip to Kenya in 2005 where the project was conceived. http://bschool.washington.edu/gsec/

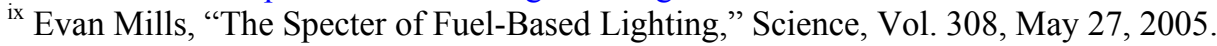

${ }^{x}$ Eckehard Doerry, "The Global Engineering College: exploring a new model for engineering education in a global economy," Proceedings of the ASEE Annual Conference, Session 1279, June 2003.

${ }^{x i}$ James Kenney, "Achieving a Global Perspective through Interdisciplinary Mini-Terms: Electric Power Development in New Zealand," Proceedings of the ASEE Annual Conference, Session 12308, June 2003

${ }^{x i i}$ Many students come to Baylor, a private university from the Baptist tradition, having had some exposure to volunteer or "mission" work. Such service, while significant in its own right, usually takes the form of unspecialized acts of kindness, such as painting houses for the poor or working in soup kitchens. Few students have ever seen service issuing out of a trained specialization or professional field. One common exception to this may be "medical missions" common in Baptist and other Christian traditions, where medical professionals volunteer in short term clinics in impoverished regions.

xiii Outcome h of the Accreditation Board for Engineering and Technology (ABET) states that engineering graduates should posses "the broad education necessary to understand the impact of engineering solutions in a global and societal context." http://www.abet.org

xiv Meredith Aronson, "Giving Back: Engaging Young Women Engineers in Community-based Design," Proceedings of the ASEE Annual Conference, Session 1392, June 2003

${ }^{\mathrm{xv}}$ Practical Action is an international organization committed to finding practical and sustainable answers to poverty. The office for East Africa is located in Nairobi. See http://www.itdg.org/.

${ }^{x v i}$ One Nairobi missionary I spoke with had his solar panels stolen by burglars but his nearby wind generator left untouched.

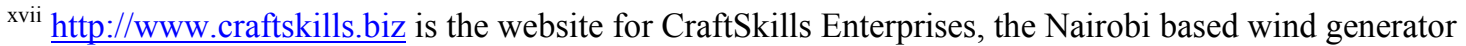
manufacturer.

xviii http://www3.baylor.edu/EngineerswithaMission is a student organization at Baylor University with the goal of using appropriate technology to serve the poor of developing countries. 